doi.org/ 10.51891/rease.v7i12.3580

\title{
A LITERATURA DISTÓPICA E A SUA OBSCURA UTOPIA
}

\author{
Erico Monteiro da Silva ${ }^{1}$
}

RESUMO: A literatura distópica, gênero literário vinculado a ficção científica, narra um futuro obscuro da humanidade frente as ações de um estado totalitário e nos fornecem possibilidades de debates críticos, tanto no campo literário quanto no campo sociopolítico. O objetivo deste artigo é discutir e apresentar os elos que compõem a distopia presente em Nós, Admirável Mundo Novo e 1984. A partir dos conceitos da literatura utópica e distópica, analisar o funcionamento do enredo em suas diversas características, principalmente o alerta sobre as consequências de idéias sociopolíticas e tecnológicas que pretendem protagonizar o progresso humano. Para esse empreendimento utilizamos os conceitos teóricos sobre utopia e distopia em Barriel (2014), Claeys (2010) e, os conceitos gerais de ficção científica em Roberts (2018). A metodologia utilizada é a bibliográfica e comparativa devido as marcas presentes estarem compartilhada, de modo geral, nas obras do (sub)gênero da ficção científica. As distopias, ao contrário das utopias e suas sociedades racionalmente felizes, demonstram um futuro catastrófico ao apresentar as tendências utópicas que se mostram modelos de realizações perfeitas para a humanidade, mas as consequências são falaciosas e totalitárias. Observamos que os autores das obras citadas utilizam sátiras utópicas como meio de crítica social ao demonstrar como seria um mundo controlado com o objetivo de prover uma distorcida felicidade e como a consciência coletiva iria se adaptar nestas realidades.

Palavras-Chaves: Ficção Científica. Utopia. Distopia.

ABSTRACT: Dystopic literature, a literary genre linked to science fiction, narrates a dark future of humanity in the face of the actions of a totalitarian state and provides us with possibilities for critical debates, both in the literary field and in the sociopolitical field. This article aims to discuss and present the links that make up the dystopia present in We, Brave New World, and 1984. From the concepts of utopia and dystopia literature, analyze the operation of the plot in its various characteristics, especially the warning about the consequences of sociopolitical and technological ideas that intend to lead the progress or human control. For this undertaking, we use the theoretical concepts of utopia and dystopia in Barriel (2014), Claeys (2010) and the general concepts of science fiction in Roberts (2018). The methodology used is bibliographic and comparative, as the marks present are generally shared in works of the (sub)genre of science fiction. Dystopias, unlike utopias and their rationally happy societies, demonstrate a catastrophic future by presenting utopian trends that prove to be models of perfect achievement for humanity, but the consequences are fallacious and totalitarian. We observe that the authors of the aforementioned works use utopian satires as a means of social criticism to demonstrate what a controlled world would be like to provide distorted happiness and how the collective conscience would adapt to these realities.

Keywords: Science Fiction. Utopia. Dystopia.

I Doutorando em Letras - Linguística pela UFPE. Mestre em Letras - Linguística pela UFPE. Graduado em Letras Português/Inglês e suas respectivas literaturas pela UFRPE-UAG. E-mail: ericgr@gmail.com 


\section{INTRODUÇÃO}

A palavra distopia suscita à imaginação déspotas que proporcionam imagens aterrorizantes de controle socioeconômico e cultural, além de dor e sofrimento provenientes de cidades em guerra ou com ilegalidade e (des)ordem calculadas. Palpáveis e próximas da verossimilhança, as distopias mostram sociedades humanas que se assemelham a um formigueiro no qual cidades são formadas por grupos distintos separados da elite que são guardados por ameaçadoras forças de segurança, enquanto as ruas testemunham longas filas de trabalhadores cansados enquanto anúncios (anti)revolucionários com normas do plano de produção saem de diversos alto-falantes.

Em virtude do caráter político, as premissas ou expectativas do leitor em encontrar no texto distópico muito mais a verossimilhança com regimes autoritários já experienciados na história ou governos atuais do que as narrativas futurísticas da evolução tecnológica, então presentes, é devido a elementos gerais da narrativa que são comumente comparadas a algum totalitarismo.

Segundo Durão (2020), a literatura é construída em um contexto histórico específico que consegue sobreviver e dialogar com tempos futuros. A distopia literária carrega em si essa característica decisiva que toca o presente. Essas características remetem à função literária que a muito suscita a discussão sobre a utilidade da literatura, função essa que Wellek e Warren (2003) afirmam que a função da literatura é nos revelar aquilo que deixamos de perceber.

A função e a utilidade da literatura distópica, essencialmente de cunho políticoideológico, se justifica ao evidenciar o totalitarismo em suas diversas facetas. A independência do texto literário sobre função e utilidade, é devido a dimensões da experiência estética que necessitam da subjetividade entre o sujeito e a obra literária, uma relação mútua de esforço recompensado com o prazer intelectual e sensorial (Durão, 2020).

O presente artigo tem o objetivo de discutir e evidenciar os elos na literatura distópica, presentes nas principais obras do (sub)gênero da Ficção Cientifica de viés político. Na busca por esses elos é preciso ir até as origens da distopia e a sua relação com a utopia; a crítica sobre as correntes ideológicas presentes nas obras; a sua pretensa função e utilidade em alertar a sociedade sobre as tendências utópicas que se mostram modelos falaciosos e autoritários de realizações perfeitas para a humanidade. 
Para o nosso empreendimento utilizamos o Método Bibliográfico e Comparativo. De acordo com Lakatos e Marconi (2012, p. 7I), “a pesquisa bibliográfica não é mera repetição do que já foi dito ou escrito sobre certo assunto, mas propicia o exame de um tema sob novo enfoque ou abordagem, chegando a conclusões inovadoras”. Não se limitando apenas na busca de um inventário de trabalhos e obras relacionados ao tema para ajudar o pesquisador na exploração do assunto, também proporciona meios de análise e ampliação das informações.

Em relação ao Método Comparativo, Lakatos e Marconi (2017, p. 107) afirmam que este "método realiza comparações, com a finalidade de verificar similitudes e explicar divergências”. Na literatura, de forma geral, o método acompanha o arcabouço teórico a qual a obra está relacionada, por exemplo, a Literatura Comparada exige que o pesquisador tenha algumas ferramentas linguísticas e históricas e tenha em mente quais os caminhos possíveis, por exemplo, para verificar os empréstimos de estilo entre autores, ou de tema em que determinado autor esteja presente em outro.

\section{A UTOPIA E A DISTOPIA LITERÁRIA - DOIS LADOS DA MESMA MOEDA}

A ficção científica, independente das suas diversas definições, é o lugar onde a arte explora a estética científica e o desenvolvimento tecnológico entre máquinas e homens (BERRIEL, 2014). A distopia explora os aspectos pessimistas do político e ideológico das sociedades sem abrir mão dos aspectos estéticos da fiç̧ão científica, porém, não toma para si o que a ficção científica tem de mais característico, o fetiche à tecnologia.

A distopia é, segundo Roberts (2018) e Clayes (2010), uma crítica radical à sociedade estruturada sobre um campo ideológico considerado negativo por seus autores. Por está razão, a comparação da literatura distópica atual com sociedades totalitárias só é possível graças a comparação de sociedades ideologicamente liberais a sociedades ditas socialistas que imaginam possibilidades utópicas de melhorias e desenvolvimento nas relações humanas, por exemplo.

Em relação a utopia, ela surge como uma esperança de uma nova sociedade que diante das possibilidades de um novo homem nascido da lógica ético-social do seu próprio tempo, funda "virtualmente uma sociedade tão perfeita em seus fundamentos que termina por impedir toda forma de desenvolvimento" (BERRIEL, 2014, p. Io). Imaginar uma sociedade feliz de forma sistemática é o que torna A Utopia (2orI), de Thomas Morus, 
diferente do imaginário cotidiano, literário e cultural de melhores condições de vida desejados desde o princípio da humanidade. Morus, como afirma Roberts (2018), imaginou uma sociedade perfeita na sua própria estrutura, não apenas em um ser individual exemplar, mas uma sociedade reimaginada.

$\mathrm{Na}$ gênese da utopia, Barriel (2014) explica que a utopia é um trabalho intelectual e ambicioso que, desde o seu nascimento, representa a subjetividade do autor sobre a sua própria sociedade, por essa razão, é um esforço intelectual datado, ao imaginar a sociedade melhor de forma sistemática com o melhor de sua época. Essa característica é marcada por um inconformismo intelectual e o desejo de mudança das formas estabelecidas no mundo. A exemplo, A Cidade do Sol, publicada em r6oz por Tommaso Campanella, surge com novos elementos ao apresentar uma cidade monárquica com desenvolvimento tecnológico e filosófico mais abrangente que a obra de Morus.

O declínio da literatura utópica se dá por um descontentamento social e mudanças advindas pela modernidade até o fim do século XIX, e é criticada por ambos os polos políticos, tornando-se um termo pejorativo muito atribuído ao pensamento socialista vigente. Berriel (2014, p. 12) explica que o "termo é vítima das críticas do pensamento burguês, mas seu descrédito deve ser atribuído igualmente a Engels, que denunciou em Saint-Simon, Fourier e Owen um 'socialismo utópico' e sentimentalmente pequenoburguês". A crítica que praticamente sepulta os chamados socialistas utópicos no campo político também recaí sobre os textos literários utópicos apesar dos questionamentos sobre o papel social e crítico da sociedade em questão.

No final do século XIX, a obra Olhando para Trás 200o-I887 (I888), de Edward Bellamy, fez um grande sucesso e fez ressurgir o interesse pelas obras utópicas. Com uma narrativa inspirada nas ideias socialistas, o protagonista, por meio de hipnose, acorda no ano 2000 e se deparada com uma sociedade coletivizada, nacionalista e com princípios solidários aboliram a pobreza e a miséria e a renda é distribuída por igual. Roberts (2014) explica que o sucesso da obra foi tão grande que desencadeou dois movimentos, o primeiro, literário com obras subsequentes e, o segundo, com críticas de cunho partidário e ideológico contra a obra, fomentando ataques contra a literatura utópica, explorando, novamente, seus aspectos sombrios.

Berriel (1999, p. 17) explica que a utopia ao revelar que "o mundo social se constrói e se destrói pela exclusiva ação humana, sem interferências sobrenaturais, sendo portanto 
passível de mudança de acordo com uma projeção anterior”, confronta o status quo ao ponto de causar horror aos mais reacionários.

O autor continua, ao afirmar que "a distopia, isto é, a fiç̧ão que cria os mundos mergulhados no pesadelo social, são utopias de sinal trocado" e por esta razão o "objetivo das distopias é analisar as sombras produzidas pelas luzes utópicas, as quais iluminam completamente o presente na mesma medida em que ofuscam o futuro" (BERRIEL, 2014, p. 17-18). Para isto se concretizar, as contrariedades naturais das utopias são exploradas a partir da experiência divergente dos autores sobre determinadas ideologias, posicionamentos políticos ou governos que se apresentem autoritários.

De acordo com Gordin, Tilley e Prakash (2010) e Berriel (2014), a utopia produz um sonho sistemático de um lugar bom resolvendo os problemas de sua época, explorando as possibilidades e o desejo de controle "voluntário" dos membros de tais sociedades em prol de um bem maior. Por outro lado, a distopia é o sonho maligno, um pesadelo social de controle dos indivíduos para resolver problemas específicos que só exitem graças aos indivíduos e grupos possuírem liberdades de pensamento, manifestações culturais e religiosos que molda a moral da sociedade. Apesar de possuírem o desejo de um futuro melhor, a principal forma de diferenciá-los é na observação dos resultados.

\section{I Características Gerais das Distopias}

A Literatura Distópica ao carregar características do ponto de vista daquilo que falha do sistema utópico, realiza as mais diversas justificativas para abusos e violências em nome de uma ordem social segura. Graças a isto, a sátira utópica inaugura as narrativas de um futuro tenebroso em que a paixão e devoção por um sistema racional nos torna apáticos e devotos de um Estado dominador que não permite as diferenças naturais. O que se segue nas obras nos permitem observar estas características.

Como sabemos, as obras distópicas retiram a inocência das utopias modernas em usar a tecnologia em favor de uma centralização da ordem social em benefício de um bem estar coletivo suspeito. Segundo Ferns (1999), as ficções utópicas argumentaram a favor do senso de domínio da humanidade sobre as condições sociais e o mundo natural, com isto, as obras de escritores como Zamiatin, Huxley e Orwell falaram e ainda falam a um público desiludido com as consequências de tais aspirações controladoras. 
Os elos de formação da distopia presentes nas obras são pontos iniciais para um entendimento do que podemos convencionar como sátira utópica. Partindo dos elementos gerais da utopia levantados por Barriel (1999), podemos elencar também as características mais comuns presentes nas obras distópicas. Dentre as principais, se destaca o isolamento no tempo e no espaço como condição de proteção à corrupção externa, um mundo fechado, homogêneo, com leis específicas que não refletem o mundo real, assim, as sociedades antecessoras possuíam apenas um passado nebuloso e um futuro trágico. A nova sociedade se situa em um ponto da história em que o presente não permite um desenvolvimento "natural" e o seu progresso não seja decorrente de uma evolução dos acontecimentos, sempre é resultado de uma intervenção salvadora posta em prática.

Com um sistema econômico fechado, exclui o dinheiro e o comércio por considerar parasitários, imorais e anti-sociais causadores das desigualdades e injustiças. Segundo Barriel (1999), o rigor das leis torna os indivíduos bons, e as instituições formam os costumes, além de considerar a lei um decreto advindo da sabedoria e da razão, de um ser mítico, o legislador. Dessa maneira, a mudança é encarada como algo ruim, um retrocesso, tão logo, qualquer agente de mudança é considerado perigoso e inútil para o Estado, e essa idéia de que o estado esteja sobre uma estrutura perfeita abre espaço para punições que utilizam de isolamento, exílio ou violência para aqueles que o totalitarismo criminaliza como opositores, dissidentes e qualquer outro com reivindicações minoritárias ou partidárias contrárias.

A uniformidade do indivíduo é outro elo marcante, pois o indivíduo é idealizado como parte de um conjunto, uma célula ou engrenagem do conjunto e, a sua vontade se confunde inconscientemente com a vontade do Estado, interpretada como justiça e progresso. Com efeito, o sacrifício dos indivíduos em prol das instituições cria dilemas entre liberdades e necessidades, que neste momento, a distopia transformaria as boas intenções em pesadelos.

Nas distopias Nós e Admirável Mundo Novo, o ser individual estaria atrelado ao Estado, o coletivismo justificaria a falta de propriedade privada como uma razão ética, garantindo a igualdade e a oportunidade do trabalho sem o parasitismo social, eliminando os conflitos decorrentes de disputas entre os indivíduos, pois não haveria mais a necessidade de pobreza, inveja ou qualquer sentimento considerado arcaico. Por outro lado, I984 é o oposto dessas idealizações, pois objetiva o controle dos indivíduos a partir da 
escassez de bens, do medo constante de um conflito e uma participação do Estado para instrumentalizar a alienação dos indivíduos.

Dos elos entre as obras, há uma base que sustenta toda a disposição ideológica sobre os indivíduos, de acordo com Barriel (1999), Roberts (2014) e Clayes (1999), a onipotência pedagógica totalitária pretendente erradicar a natureza primitiva, individual e conflituosa do humano. Cabe unicamente ao Estado a missão de construir e manter a ordem social e suas leis e, com isto, introjetar tal ordem e regras modelando a mentalidade do indivíduo à estrutura social, suprimindo qualquer vontade de dissidência do sujeito cativo.

Da mesma forma, a família é suprimida ou inexistente na distopia, muito por conta dos objetivos de controle e educação infantil tutelados unicamente pelo Estado. Podendo ir além, estabelecendo o controle a partir do nascimento até a vida adulta (BARRIEL, I999; ROBERTS, 1999). O mesmo ocorre com a religião, em que a divindade é suprimida ou substituída pela figura mítica de um bem feitor criador ou protetor, ou seja, é atribuído ao Estado Totalitário ou um governante/fundador a figura de divindade.

\subsection{Os Elos das Obras Distópicas}

Nós (2017), obra-prima do escritor russo Iêvgueni Zamiátin, publicada em 1920 nos Estados Unidos, inaugura o romance literário distópico. Apesar de não possuir o ineditismo quanto à critica a utopias ou à ideais políticos, já esboçados em A Nova Utopia, de Jerome K. Jerome, publicada em I89I, um conto que satiriza os ideais socialistas vigentes, a obra de Zamiátin foi, sem dúvida, a obra que mais influenciou as demais obras distópicas do século XX.

De acordo com Fitting (2010), o romance de Zamiánti crítica a própria ideia de querer um mundo melhor, a partir de um sistema político, social, cultural e, principalmente, religioso. A crítica da sociedade contemporânea do autor, a Rússia Stalinista, não implicava a necessidade de mudança, pois há uma defesa do status quo da sociedade e uma caricatura daquilo que Zamiátin considerou perverso aos indivíduos.

A narrativa de Nós, para Roberts (2018), rejeita a razão iluminista por entender ser cruel, além de ditatorial, também equipara essa racionalidade como uma opressão à religião cristã. Esse posicionamento de Zamiátin é bastante comum devido a distorcida interpretação do humano como máquina advinda do que eles interpretaram como ideais bolcheviques de um humano ideal. 
Partindo do ponto de vista do narrador e protagonista, D-503 descreve em um diário de anotações seu dia a dia e a sua missão de construir, em grupo, uma espaçonave chamada Integral, com o objetivo de conquistar o espaço e converter extraterrestres. É por meio de D-503 que enxergamos a sátira a utopia presente na obra e a devoção racionalizada daquilo que se entende como superior ao passado. Assim como as novas ideias e aspirações ideológicas tendem a superar aquilo que julgam ultrapassado e danoso, Zamiátin utiliza a Integral como uma analogia a expansão da ideologia do Estado Único, quando D-503 afirma que um

\begin{abstract}
Grande momento histórico está próximo, quando a primeira INTEGRAL alçará voo para o espaço. Há mil anos, vossos heroicos antepassados submeteram todo o globo terrestre ao poder do Estado Único. Uma façanha ainda mais gloriosa está pela frente: integrar a infinita equação do universo com a INTEGRAL de vidro, elétrica e que cospe fogo. Espera-se submeter ao jugo benéfico da razão os seres desconhecidos, habitantes de outros planetas, que possivelmente ainda se encontrem em estado selvagem de liberdade. Se não compreenderem que levamos a eles a felicidade matematicamente infalível, o nosso dever é obrigá-los a serem felizes. Mas antes de recorrermos às armas, empregaremos a palavra. (ZAMIÁTIN, 2017, P. 16).
\end{abstract}

Na distopia de Zamiátin, o Estado Único controla seus cidadãos, os Números, com precisão matemática, lógica, pois todas as tarefas diárias são organizadas por um rígido cronograma. A crença e a ideologia são baseadas na idéia de que a privacidade precisa de um objetivo coletivo, a individualidade, os desejos e o livre-arbítrio são as responsáveis pela infelicidade. A ausência de deus é justificada pela ilogicidade da sua existência, cabendo ao Benfeitor esse papel de manter o Estado Único provedor do paraíso terreno.

Roberts (2018) destaca que a privacidade seja um ponto inconsistente na obra, ora por todos morarem em casas de vidros e poderem ser vistos, os momentos íntimos poderiam ser interpretados como perigosos, já que o Estado Único dispunha do "olhar experiente dos Guardiões" (ZAMIÁTIN, 2017, p. 33), muito embora, essa tenha sido a intenção do autor.

A falta de individualidade é expressa nos personagens nomeados com letras e números, assim a personalidade e os desejos individuais são associados a personalidade e desejos do Estado Único, um sentimento de pertencimento "os números marchavam marcando o compasso, entusiasmados - centenas, milhares de números em uniformes azulados, placas de ouro no peito com o número estatal de cada homem e mulher. E eu era - nós quatro - uma das infinitas ondas dessa poderosa corrente" (ZAMIÁTIN, 2017, p. 2I). 
A entidade divina é um dos elementos característicos da utopia, segundo Berriel (2014), a religião é amalgamada à ilha, à sociedade ou a própria utopia. Zamiátin fundi a entidade ao próprio Estado Único de uma forma clara ao comparar as celebrações e devoções ao Estado Único e ao Benfeitor como as cerimônias eucarísticas, porém, as cerimonias

Serviam a um Deus absurdo e desconhecido, ao passo que nós servimos a um Deus plausível e cuja imagem é precisamente conhecida; o Deus deles não lhes deu nada além de uma busca eterna e torturante; o Deus deles não imaginou nada mais inteligente do que oferecer-se em sacrifício, sem saber por quê; nós nos sacrificamos a Deus, ao Estado Único com calma, de maneira bem pensada, um sacrifício racional. Sim, essa era a liturgia solene do Estado Único (ZAMIÁTIN, 2017, p. 73).

Zamiátin satiriza o endeusamento do estado soviético opondo-se aos ideias bolcheviques, não na essência dos ideias que o mesmo comungava no inicio da Revolução Russa, na obra ele critica a radicalização dos membros do partido e a ideia cartesiana do homem (SLUSSER, 20II). Por essa razão que Zamiátin escreve sobre o espirito do ser humano, a alma primitiva, aquilo que o Estado Único e o Benfeitor não conseguem dominar por completo. De certo, D-503 entrega-se à Operação, mas apenas quando encontra uma linguagem que possibilite compreender seus sentimentos e a importância da rebelião.

A trama termina sombria, com uma suposta vitória do Estado Único em conter a rebelião ao descobrir que os indivíduos contrários ao governo de Utopia sofriam de imaginação e D-503 é submetido a tal procedimento que o faz perder a "alma" e logo o que se imaginaria, entrega a todos à polícia. A sua mudança é clara, pois ele assiste I-330, personagem que desperta nele o amor e a paixão, ser torturada com gás comprimido sob uma redoma.

Para Roberts (2018) a obra termina de modo a sugestionar que a resistência esteja dominando pontos importantes, apesar do seu final melancólico, de certa forma. $\mathrm{Na}$ resenha de George Orwell sobre a obra, ele explicita o quanto ela é importante e impacta por mostrar o lado perverso do totalitarismo, mais precisamente na execução dos inimigos, que com efeito

a execução é um sacrifício humano, e a cena que a descreve recebe deliberadamente a cor das sinistras civilizações escravocratas do mundo antigo. É esta apropriação intuitiva do lado irracional do totalitarismo sacrifício humano, crueldade como um fim em si, idolatria de um Líder a quem se atribuiu características divinas - que faz do livro de Zamiátin superior ao de Huxley (ORWELL, 2017, p. 321). 
Os elementos centrais que constituem as narrativas distópicas presentes em Nós, na obra de Aldous Huxley ganharam dimensões mais serias, sem o humor da obra de Zamiátin que retira os aspectos sombrios, Admirável Mundo Novo (2003), publicado em 1942, além de antiutopista, também cristaliza a ideia antimáquina do ser humano, como também, a ideia de desenvolvimento e bem-estar social atrelada ou condicionada às máquinas e uma espécie de estratificação social. Porém, a obra de Huxley não se limita apenas ao nível de conteúdo, constrói a crítica a partir da lógica das utopias ao construir seu enrendo sobre duas perspectivas. $\mathrm{O}$ compromisso da literatura distópica é estar sempre comprometida com uma hierarquia formal do sistema (GLAYES, 2017) e essa característica presente na obra traz a dualidade utópica e distópica em confronto, motivo que até hoje os leitores mais atentos sentem dificuldades em classificar o texto, apesar das cenas de abertura e o contexto narrativo favorecer, seguramente, a interpretação distópica.

Roberts (2018) alega que a qualidade definidora da sociedade criada por Huxley é a estabilidade da felicidade humana proporcionada pelos avanços científicos e a organização social e educacional do Estado. Essa estrutura é gerenciada sobre os lemas comunidade, estabilidade e identidade, como demonstra Mangini et al (2014), esses lemas são representações institucionais comandadas por uma minoria que concentra poder e conhecimento em nome de uma utopia de paz, conforto e felicidade.

A história ocorre no ano de 637 d.F. (637 anos depois de Ford), após uma grande guerra que ameaçou a existência humana, uma administração de nível global foi instalada e uma sociedade baseada nos princípios da engenharia especializada, organizada em castas e ideologicamente taylorizada (ROBERTS, 2018).

Em resumo, na sociedade de Admirável Mundo Novo, as castas são formadas por Alfa, Beta, Gama, Delta e Ípsilon. Cada uma delas possuíam funções de acordo com a hierarquia social definidas por eugenia, os Alfas são os superiores que estão no ápice da sociedade e ocupam cargos de liderança, são os profissionais especialistas; os Betas ocupam posição de média hierarquia e ocupam cargos técnicos; os Gamas, os Deltas e os Ípsilon ocupam posições de menor prestigio hierárquico por serem considerados inferiores, são delegados os trabalhos manuais e menos exigentes intelectualmente - os trabalhos mais arriscados, sujos e até degradantes são destinados a essas castas.

A solidariedade promovida por diversas estratégias ideológicas, doutrinação e por meio do condicionamento biológico e psicológico que faziam com que os indivíduos 
naturalizassem as condições de servos obedientes e resilientes como algo próprio a si mesmos, amando o status social a que pertencem, principalmente os subalternos das castas inferiores. Desse modo, não haviam disputas, pois a casta a que pertenciam desde o nascimento era imutável.

Para manter a estrutura utópica, os indivíduos possuíam longevidade, eram livres de doenças, estavam em constante estado de felicidade, sempre produtivos e consumistas. Os alimentos eram fornecidos pelo Estado em forma de rações, além de uma droga chamada Soma. O sexo promíscuo era uma das formas de lazer e as manifestações culturais e intelectuais substituídas por instituições que instrumentalizam as sensações odoríferas e táteis. Para sustentar essa estrutura social, a reprodução artificial in vitro e uma espécie de clonagem, eram responsáveis pela reprodução humana. No Estado Mundial, instituição responsável pela reprodução, os técnicos e dirigentes selecionavam e condiziam a diferenciação e padronização dos indivíduos. No processo, apenas os Alfas eram aprimorados, enquanto os indivíduos de castas inferiores sofriam retardamentos por meio de condicionamentos diversos com o objetivo de manter uma padronização e controle dos operários, já que eram produzidos em massa graças a técnica de Processo de Bokanovsky.

Mangini et al (2014) explica que a condição da existência da sociedade do romance de Huxley era a Estabilidade, uma entidade institucional na qual o controle da subjetividade consistia nos métodos de condicionamento considerados seguros e eficientes, ao contrário da violência e qualquer método punitivo violento, como prisões, consideradas ineficazes. O poder, a fonte da dominação fora internacionalizado, o condicionamento transferira para a mente das pessoas o controle necessário para que a submissão fosse forte o suficiente e sutil ao ponto de não perceberem tal dominação ideológica, se sentiam livres.

Mantendo o controle dos indivíduos a partir do controle das emoções e por meio dos avanços técnicos da medicina para gozarem de saúde e longevidade, qualquer instituição que ocasionava particularidades subjetivas difíceis de controlar eram extintos. Essas instituições eram a família, substituída pela reprodução artificial e pela sexualidade liberta sem qualquer compromisso afetivo, já que não possuía a responsabilidade pela reprodução e meio de intimidade e, por representar desejos particulares e possessivos. A arte e a religião também eram encaradas como um perigo à estabilidade social e à identidade dos próprios indivíduos. Assim como o conhecimento era considerado, principalmente para as castas intermediarias e inferiores, algo abominável. A justifica para 
abolirem a família, a arte, a religião e o interesse para com o conhecimento era a possibilidade dessas instituições sociais ocasionarem sofrimentos, tanto por responsabilidades que privavam os desejos e a liberdade, quanto as emoções subjetivas despertas por sofrimentos e sentimentos de tristeza e melancolia.

No mundo criado por Huxley, a felicidade constante, o trabalho $e$ os condicionamentos faziam com que não existissem disputas e com isso o lema de todos trabalharem em prol da coletividade era a marca da utopia desse universo, tanto que as diferenças eram apenas por castas e não por uma individualidade subjetiva e privada.

O ponto de virada é a presença do personagem Barnard Marx que viaja para uma reserva onde os chamados selvagens vivem em pequenas comunidades. Marx encontra um selvagem filho de uma civilizada que fora abandonada por engano na reserva e o leva a civilização. Por meio deste selvagem chamado John que Huxley expõem a distopia presente na obra. Devido a sua ingenuidade, as emoções amadurecidas e os conhecimentos adquiridos na reserva, fazem com que as tentativas de condicionamento fracassem. Como salienta Roberts (2018), os embates entre John e o administrador Alfa plus, Mustafá Mond, um dos dez Controladores do Mundo (personagem lucido, esclarecido e com individualidade própria o suficiente para ter escolhas), explicitam toda a sátira a utopia de Admirável Mundo Novo e revela os pontos obscuros nela presente, como a eugênia, privação de liberdade, de identidade e conhecimento científico verdadeiro, obediência acrítica, falsa felicidade, consumismo exacerbado, vicio em alucinogênico, hedonismo banal e, talvez o ponto central da obra, a falta de consciência ao divino, aquilo que dá consciência ao homem e um objetivo, aquilo que lhes faltam.

Para Roberts (2018, p. 360), Admirável Mundo Novo "eleva a Ficção Cientifica como gênero a uma espécie de conclusão lógica antimística, a um mundo - feliz, saudável, brando - purgado de magia religiosa”. Expresso no diálogo entre Mond e John, o administrador deixa claro que "Deus não é compatível com as máquinas, a medicina científica e a felicidade universal" (p. 284), a existência de um deus advêm da necessidade e a necessidade abolida da sociedade de Admirável Mundo é justifica por Mond ao dizer que

Agora nós temos juventude e prosperidade até o fim. O que resulta daí? Evidentemente, que podemos prescindir de Deus. "O sentimento religioso nos compensará de todas as nossas perdas." Mas não há, para nós, perdas a serem compensadas; o sentimento religioso é supérfluo. E por que iríamos em busca de um sucedâneo dos desejos infantis, se esses desejos nunca nos faltam? De um sucedâneo das distrações, quando continuamos desfrutando todas as velhas tolices até o fim? Que necessidade temos de repouso, quando nosso corpo e nosso 
espírito continuam deleitando-se na atividade? De consolo, quando temos o soma. De alguma coisa imutável, quando temos a ordem social? (p. 282).

A ausência de um ser divino não está na ordem da sua existência ou não, Huxley deixa claro que para os civilizados de casta superior, deus ou qualquer divindade é uma crença fundamentada no condicionamento da sua época, na falta de organização e superação da dor e qualquer tipo de sofrimento, pois deus é a busca da superação aos males da humanidade.

Diferente das distopias que lhe antecederam, 1984, de George Orwell, escrita em 1948, carrega toda a experiência da brutalidade dos regimes totalitários reveladas no pósguerra. A obra é vista como uma extrapolação dos regimes totalitários das décadas de 30 e 40 do século 20. Importando as fatalidades decorrentes das crises econômicas e das instabilidades políticas como justificativa para o seu estado distópico, o ponto principal da obra é descrever a estrutura e o funcionamento desse tipo de realidade política, partindo dos fundamentos ideológicos até a miserável qualidade de vida imposta a maioria dos seus cidadãos.

A obra narra um futuro em que o mundo é dividido entre três estados-nações governados por regimes absolutistas, a Oceania (compreendia os países do Continente Americano, a Grã-Bretanha, a Islândia, Irlanda, a Austrália e a África do Sul), a Eurásia (compreende a Antiga União Soviética e a Europa continental) e a Lestásia (China, Ásia Oriental e Japão) e, em constante clima de guerra, os territórios remanescentes estão sempre em disputa.

A história se concentra no Partido Único da Oceania, governo este que segue os princípios do Ingsoc, ou socialismo inglês. Como observa Roberts (2018) a Oceania é um governo inspirado no sistema estatal stalinista, dessa forma, a sátira presente na obra não remete às utopias de forma direta, mas satiriza os regimes totalitários. Segundo Clayes (2010), Orwell combinou certos temas anti modernistas e anti capitalistas com uma hostilidade ao stalinismo e ao fascismo.

Para Clayes (2010), a obra espelhava ou distorcia um mundo totalitário ao mesmo tempo que representou uma rejeição de alguns aspectos da modernidade como a esperança de um futuro melhor, mesmo com a existência de uma concentração de poder por parte de uma minoria, também representou a preocupação que Orwell sentia dos intelectuais do movimento socialista que corrompidos pelo culto ao poder inevitavelmente não funcionariam como lideres capazes ou moralmente honestos em qualquer sociedade. 
Assim como Zamianti, Orwell reconhecia que o problema central para um projeto de sociedade futura, viável ou não, dependia dos líderes dessa sociedade.

No desenvolvimento da trama, acompanhamos o Winston Smith, um medíocre habitante da Pista UM que almeja mudanças a partir de uma rebelião interna, mas seus crimes se resumem a escrever um diário com pensamentos e ideais dissidentes e ter um caso com Júlia, já que o sexo sem o objetivo de procriação é considerado crime. A estrutura social é organizada de forma hierarquizada, no topo há o Grande Irmão e abaixo dele, o Partido Interno, o Partido Externo e os Proles.

O Grande Irmão é uma entidade criada pelos integrantes do Partido Interno, a cúpula do Estado, que mantêm os integrantes do Partido Externo, no qual Winston faz parte, ocupados e vigiados todo o tempo. Os dispositivos de controle do Estado são as extensas horas de trabalho ao pertencentes ao Partido Externo, os Dois Minuto de Ódio, a Semana do Ódio, o duplipensar, a novilingua, a teletela, o Patrulhamento do Pensamento.

As justificativas e os meios para tornarem os cidadãos cativos tem relação direta com a manutenção de poder de uma minoria que usufruí dos bens de consumo e boa qualidade de vida, enquanto os indivíduos do Partido Externo e da Prole vivem com o mínimo ou menos, a violência e a degradação do indivíduo aqui não são empregada apenas como uma forma de castigo, mas um recurso de dominação do indivíduo ao Estado. O medo alimentado pela ininterrupta possibilidade de invasão pelos outros Estados garante a subserviência àquele protetor e benfeitor ao que todos admiram ou amam, o Grande Irmão. Mas na verdade o objetivo de manter essa subserviência e os instrumentos de alienação, vigilância e violência são opções já que

Era possível imaginar uma sociedade na qual a riqueza, no sentido de bens e luxos pessoais, fosse distribuída equitativamente, enquanto o poder permanecia nas mãos de uma pequena casta privilegiada. Na prática, porém, uma sociedade desse tipo não poderia permanecer estável por muito tempo. Porque se lazer e segurança fossem desfrutados por todos igualmente, a grande massa de seres humanos que costuma ser embrutecida pela pobreza se alfabetizaria e aprenderia a pensar por si; e depois que isso acontecesse, mais cedo ou mais tarde essa massa se daria conta de que a minoria privilegiada não tinha função nenhuma e acabaria com ela. A longo termo, uma sociedade hierárquica só era possível num mundo de pobreza e ignorância. (ORWELL, 2019, p. 24I).

Roberts (2018, p. 459) faz uma interessante observação sobre a Ficção Cientifica presente na obra ao afirmar que apesar da tecnologia está presente, ela é exposta em metáforas como: 
As teletelas, as bombas-foguetes, as avançadas tecnologias da guerra. Mas em outro sentido, no regime da novela a tecnologia não tem utilidade. A divisa sobre controlar o futuro é circular por completo; não há futuro em Oceania, só um contínuo presente de poder partidário. Até mesmo a data do título reforça essa noção; escrevendo em 1948, Orwell apenas inverteu os dois últimos algarismos para obter sua data fictícia. (ROBERTS, 2018, p. 459).

$\mathrm{Na}$ passagem do livro, Winston lê um livro considerado proibido e nele há revelações que explicam e justificam o porquê das tecnologias serem rudimentares $e$ propositadamente instrumentalizadas para os fins do Grande Irmão - com o avanço rápido da tecnologia antes da grande guerra, ou seja, antes da destruição proveniente das bombas atômicas que arrasaram o mundo na década de 50 e pouco se fez para sanar a destruição, a complexidade do desenvolvimento dos Estados Nações está no avançado uso dos recursos naturais e a autossuficiência das mesmas em prover o necessário para a maioria e o acumulo de bens para a uma minoria.

Assim, não há motivos para a guerra por expansões de mercado, o que ocorre é a busca de mão de obra barata nas regiões de conflito, a falta de desenvolvimento tecnológico proporciona uma não "existência de um futuro para o qual os habitantes da sociedade de Orwell possam avançar" (ROBERTS, 2018, p. 46o), por isso o controle da história e a manipulação da linguagem se faz necessário, além do que,

Os perigos inerentes à máquina continuam existindo. Assim que ela surgiu, ficou claro para todas as mentes pensantes que os homens já não seriam obrigados a trabalhar - e que, como consequência, em grande medida a desigualdade entre eles também desapareceria. Se a máquina fosse usada deliberadamente para esse fim, a fome, o trabalho duro, a sujeira, o analfabetismo e a doença desapareceriam em poucas gerações. (ORWELL, 2019, p. 240).

Como visto no livro proibido, a manutenção da guerra ininterrupta também é uma técnica para mascarar o objetivo de manter a retenção de bens mais efetiva, pois evitasse que a privação fosse percebida como um programa de Estado, impedindo o surgimento de opositores. Com o fim do Capitalismo, os habitantes dos Estados Nações, impedidas de trabalhar, mas assistidas pelo Estado, provocava um estado de semi-inanição nos habitantes e o enfraquecimento do poderio militar. Como os bens não poderiam ser distribuídos às massas, mesmo que privação fosse desnecessária,

O ato essencial da guerra é a destruição, não necessariamente de vidas humanas, mas dos produtos do trabalho humano. A guerra é uma forma de despedaçar, de projetar para a estratosfera ou de afundar nas profundezas do mar materiais que, não fosse isso, poderiam ser usados para conferir conforto excessivo às massas e, em consequência, a longo prazo, torná-las inteligentes demais (ORWELL, 2019, p. 242). 
Essa preocupação excessiva em não permitir que os indivíduos se tornem independentes e detentores dos bens de consumo e conhecimento é o desejo de tornar o indivíduo pertencente ao Estado, ou seja, o sujeito condicionado, como afirma Pavloski (2014), em estado de terror é prisioneiro, isto significa que os cidadãos partidarizados são componentes do Estado, tanto Interno quanto Externo. Dessa forma, Roberts (2018, p.462) chega a conclusão que a obra de Orwell não é sobre seus personagens, mas sobre a evolução de um ser "todo-poderoso, onisciente, uma forma de Deus secular que se originou da humanidade [...] (é) um trabalho muito mais de vanguarda do que a maioria das pessoas pode se dar conta". Precisamente, é a utopia de uma minoria em busca de poder, um poder militarizado que conhece as possibilidades humanas e por essa razão manipula a linguagem e a percepção dos acontecimentos para manter o que falha da utopia seu instrumento de dominação, mas com um agravante, essas falhas são propositais.

\section{CONSIDERAÇÕES FINAIS}

Os elos que caracterizam o gênero de ficção cientificam distópica abarcam diversas camadas sombrias e exploram os elementos que escapam dos efeitos positivos das utopias. De forma geral, o elo mais evidente está na função da literatura distópica em alertar a sociedade dos perigos dos ideais utópicos que almejam resolver os problemas de uma sociedade de forma sistemática. Os principais autores da fiç̧ão distópica utilizaram a sátira utópica como forma de crítica aos pensamentos de grupos ideológicos vigentes para explicitar suas preocupações e receios com o andamento da sociedade moderna das primeiras décadas do século XX. Em virtude do caráter político, as premissas ou expectativas do leitor em encontrar no texto distópico muito mais a verossimilhança com regimes totalitários já experienciados na história ou governos atuais do que as narrativas futurísticas da evolução tecnológica então presentes, é devido a alguns elementos gerais da narrativa serem comparadas a algum totalitarismo. Os autores das obras referenciadas demonstram como seria um mundo perfeito aos olhos tirânicos de um estado ou líder que propicia os meios para a felicidade.

Em Nós, de Zamiátin (2017), ao utilizar e ampliar o mesmo contexto da sociedade de Uma Nova Utopia, de Jerome K. Jerome, a sua crítica não recai sobre um governo ou sociedade especifica, tendo em vista que o autor foi perseguido tanto por Czaristas quanto por Bolcheviques, sua sátira a utopias que projetam modelos de um homem ideal e uma 
sociedade perfeita, lógica e racional, explora a própria irracionalidade do totalitarismo em sacrificar os indivíduos em nome de uma crença na felicidade que precisa ser expressa sem ambiguidades, sem a interpretação subjetiva, apenas a racionalidade de uma máquina pensante.

A obra de Zamiátin influenciou diversos autores, mesmo que Huxley afirme que Admirável Mundo Novo não fora inspirado em Nós, é inegável a presença de diversos elementos em comum entre elas, como o controle da vida privada, do desejo sexual, da individualidade, pontos centrais para os regimes coletivistas distopicos. O tema central da obra de Huxley é o avanço da ciência sobre o indivíduo, o trabalho e o resultado da eugênia como aperfeiçoamento do homem. A sátira utópica não recaí negativamente sobre a eugênia, mas sim, na aplicação da engenharia comportamental para perpetuar o sistema de classes existente e assim, perpetuar a condição dos menos favorecidos à ignorância e estupidez. Desta forma, a sátira recaí sobre os meios de comunicação e propaganda para tornar a população entorpecida, uma crítica direta ao capitalismo que gera implacavelmente estupidez e dependência aos bens de consumo.

$\mathrm{Na}$ obra de Hixley, os avanços tecnológicos poderiam tanto ajudar quanto prejudicar a sociedade, mas era algo neutro, pois os efeitos negativos e positivos dependiam da sociedade que em nome de uma felicidade e total ausência de dor e sofrimentos substituíram qualquer comportamento que necessitasse de responsabilidade em qualquer nível social, individual ao hedonismo exagerado, ao uso de alucinogênico e o consumismo.

Como vimos, a obra 1984, de Orwell faz contraste com Admirável Mundo Novo nas possibilidades do controle por meio da punição dos comportamentos indesejáveis. Enquanto Huxley satirizava o sistema de recompensas por comportamentos desejáveis, Orwell desenhava o terror, o medo e a manutenção do ódio por inimigos imaginários como forma de manipulação, além do controle sobre a linguagem e a possibilidade de compreensão da realidade.

A fragilidade da memória é o tema central de i984. O Partido constantemente reescreve o passado e este passado deve estar em concorrência com outros passados até o momento que se torne a verdade absoluta, impedindo qualquer possibilidade de futuro. É na figura do personagem Winston que a verdade e as versões dela permanecem e isto 
implica não apenas a necessidade do personagem em mostrar a infalibilidade do Big Brother e do Partido, mas a sua capacidade de ter lembranças duradouras dos sentimentos de afeto. No entanto, ele começa a questionar sua própria capacidade de recordar diferentes momentos do passado que contradizem a linha atual.

A nossa conclusão é que as literaturas distópicas funcionam como críticas sociais e políticas, funcionando como um alerta às tendências utópicas que se mostram modelos de realizações perfeitas para a humanidade, mas as consequências são falaciosas e totalitárias. Observamos que os autores das obras citadas utilizam contextos narrativos em comum para demonstrar como seria um mundo dominado e como a consciência coletiva iria se adaptar nestas realidades.

\section{REFERÊNCIAS}

BERRIEL, Carlos Eduardo Orneias. Prefácio. In.: BIANCHETTI, Lucídio; THIESEN, Juares da Silva. Utopias e distopias na Modernidade: educadores em diálogo com $\mathrm{T}$. Morus, F. Bacon, J. Bentham, A Huxley e G. Orwell. Ijuí: Editora Unijuí, 2014.

CLAEYS, Gregory. The Origins of Dystopia. In: Utopian Literature. Cambridge: NYU Press, 2010. p. 107 - 134.

Dystopia - A Natural History. Oxford: Oxford University Press, 2017.

DURÃO, Fabio Akcelrud. Metodologia de Pesquisa em Literatura. São Paulo: Parabóla, 2020.

FERNS, Chris. Narrating utopia - Ideology, Gender, Form inUtopian Literature. Liverpool: Liverpool University Press, 1999.

FITTING, Peter. Utopia, dystopia and science fiction. In.: Claeys, Gregory. The Cambridge companion to utopian literature. New York: Cambridge University Press, 2010. p. $135-153$.

GORDIN, Michael D.; TILLEY, Helen; PRAKASH, Gyan.Utopia/dystopia: conditions of historical possibility. New Jersey: Princeton University Press, 2010.

HUXLEY, Aldous. Admirável Mundo Novo. São Paulo: Globo, 2003.

LAKATOS, Eva Maria; MARCONI, Marina de Andrade. Metodologia do trabalho científico: projetos de pesquisa, pesquisa bibliográfica, teses de doutorado, dissertações de mestrado, trabalhos de conclusão de curso. São Paulo: Atlas, 2017.

LAKATOS, Eva Maria; MARCONI, Marina de Andrade; Técnicas de pesquisa: planejamento e execução de pesquisa; amostragens e técnicas de pesquisa; elaboração, análise e interpretação de dados. In: Técnicas de pesquisa: planejamento e execução de pesquisa; amostragens e técnicas de pesquisa; elaboração, análise e interpretação de dados. 2012.

ORWELL, George. 1984. São Paulo: Companhia das Letras, 2019. 
ORWELL, George. Resenha de Nós, de Ievguêni Ivánovitch Zamiátin. In.: ZAMIÁTIN, Ievuêni I. Nós. São Paulo: Aleph, 2017. p. 316-323.

MANGINI , Fernanda Nunes da Rosa et al. Educação, Trabalho e Tecnologia no Admirável Mundo Novo: entre a realidade e a ficção. In.: BIANCHETTI, Lucídio; THIESEN, Juares da Silva. Utopias e distopias na Modernidade: educadores em diálogo com T. Morus, F. Bacon, J. Bentham, A Huxley e G. Orwell. Ijuí: Editora Unijuí, 2014.

PAVLOSKI, Evanir. 1984: a distopia do indivíduo sob controle. Ponta Grossa: Editora UEPG, 2014 .

SLUSSER, George. Descartes Meets Edgar Rice Burroughs: Beating the Rationalist Equations in Zamiatin's We. Canadian-American Slavic Studies. v. 45, n. 3-4, p. 307-328. 2011. Disponível em: https://brill.com/view/journals/css/45/3-4/css.45.issue-3-4.xml. Acesso em: 20 Dez. 2021.

WELLEK, René; WARREN, Austin. Teoria da Literatura e Metodologia dos Estudos Literários. São Paulo: Martins Fontes, 2003.

ZAMIÁTIN, Ievuêni I. Nós. São Paulo: Aleph, 2017. 